\title{
High glucose promotes the osteogenic differentiation capability of human periodontal ligament fibroblasts
}

\author{
SUJIWAN SEUBBUK ${ }^{1}$, HATHAITIP SRITANAUDOMCHAI ${ }^{2}$, JULALUX KASETSUWAN $^{3}$ and RUDEE SURARIT $^{2}$ \\ ${ }^{1}$ Molecular Medicine Program, Faculty of Science; ${ }^{2}$ Department of Oral Biology; \\ ${ }^{3}$ Department of Oral Medicine and Periodontology, Faculty of Dentistry, \\ Mahidol University, Ratchthewi, Bangkok 10400, Thailand
}

Received January 27, 2016; Accepted January 16, 2017

DOI: $10.3892 / \mathrm{mmr} .2017 .6333$

\begin{abstract}
Periodontal ligament fibroblasts (PDLFs) are important cells, which are involved in maintaining tooth integrity. Diabetes has been found to be associated with periodontal disease in a bidirectional manner. The aim of the present study was to investigate the stemness properties of human PDLFs (HPDLFs) in high glucose conditions. HPDLFs were analyzed for their osteogenic differentiation capacity by inducing the cells with osteogenic medium in various glucose concentrations. The gene expression was then examined using reverse transcription-quantitative polymerase chain reaction analysis, and examinations of alkaline phosphatase activity and nodule formation were performed. The results of the gene expression analysis revealed that high glucose media induced the expression of NANOG, octamer-binding transcription factor 4, (sex determining region Y)-box 2, cluster of differentiation 166 (CD166), PERIOSTIN and $\beta$-CATENIN following culture of the cells for 3 days. Alkaline phosphatase activity increased following 14 days in the high glucose condition. In addition, higher numbers of calcified nodules were formed on day 28 in the group cultured with high glucose. The results showed that high glucose induced bone formation by elevating the expression of stem cell markers, particularly $C D 166$, and this induction may be regulated through $\beta$-CATENIN.
\end{abstract}

\section{Introduction}

A high blood glucose level is characteristic of diabetes mellitus (DM), a disease resulting from abnormal insulin levels or an abnormal response to insulin. Patients with DM are prone to several complications, including periodontitis. A previous

Correspondence to: Dr Rudee Surarit, Department of Oral Biology, Faculty of Dentistry, Mahidol University, 6 Yothi Road, Ratchthewi, Bangkok 10400, Thailand

E-mail: rudee.sur@mahidol.ac.th

Key words: periodontal ligament fibroblasts, osteogenic differentiation, high glucose, periodontitis, diabetes mellitus longitudinal study showed that the prevalence of periodontitis increased with an odds ratio of 4.23 in diabetic patients (1). Increased alveolar bone loss is also found in diabetic patients with poor glycemic control (2).

The periodontal ligament, a component of periodontal tissue, consists of heterogenous cells and is involved in tissue regeneration. Several studies (3-5) have shown that periodontal ligament fibroblasts (PDLFs) express mesenchymal stem cell markers and can differentiate to become osteoblasts, adipocytes and chondrocytes. Under hyperglycemic conditions, PDLFs can induce apoptosis through the caspase-3 signaling pathway $(6,7)$. In addition, high glucose levels induce the expression of fibronectin receptor (8), which may result in delayed wound healing in diabetic patients with severe periodontitis. However, the stem cell properties of PDLFs in high glucose remain to be fully elucidated. Therefore, the present study aimed to investigate the effect of different glucose conditions on the stemness properties of human PDLFs in order to improve understanding of the biology of these cells in diabetic patients, which may lead to improved dental treatment.

\section{Materials and methods}

Cell culture. The HPDLFs were purchased from ScienCell Research Laboratories (Carlsbad, CA, USA). The HPDLFs were routinely cultured in Dulbecco's modified Eagle's medium (DMEM; Thermo Fisher Scientific, Inc., Waltham, MA, USA) supplemented with $10 \%$ fetal bovine serum (FBS; Hyclone; GE Healthcare Life Sciences, Logan, UT, USA) and antibiotic/antimycotic solution containing $100 \mathrm{U} / \mathrm{ml}$ penicillin $\mathrm{G}, 100 \mu \mathrm{g} / \mathrm{ml}$ streptomycin and $0.025 \mu \mathrm{g} / \mathrm{ml}$ amphotericin B (Thermo Fisher Scientific, Inc.). The HPDLFs were maintained in a humidified atmosphere at $5 \% \mathrm{CO}_{2}$ at $37^{\circ} \mathrm{C}$ and were subcultured at confluence. The culture medium was replaced every 2-3 days. The HPDLFs used in the present study were those in passages 5-9.

To examine the effect of a high glucose concentration on HPDLFs, the cells were cultured in three types of medium: Normal glucose (NG), high mannitol (HM) and high glucose (HG). The NG medium contained $5.5 \mathrm{mM}$ of D-glucose, simulating the normal blood glucose level in humans. The HG medium contained $25 \mathrm{mM}$ of D-glucose, whereas the 
HM medium was used as an osmotic pressure control, which contained 5.5 mM of D-glucose and 19.5 mM D-mannitol.

Proliferation assay. A 3-(4,5-dimethylthiazol-2-yl)-2,5diphenyltetrazolium bromide (MTT) assay, a quantitative colorimetric assay, was used to estimate cell viability and cell proliferation. The principle of the assay is that MTT, a yellow tetrazole, is metabolized by mitochondrial succinate dehydrogenase in living cells to a purple formazan product.

The HPDLFs were seeded in 24-well plates $\left(\right.$ Costar $^{\circledR}$; Corning Incorporated, Corning, NY, USA) at a density of $2 \times 10^{4}$ cells/well in a humidified atmosphere at $5 \% \mathrm{CO}_{2}$ at $37^{\circ} \mathrm{C}$. Following incubation for $24 \mathrm{~h}$, the time was set as day 0 and the medium was replaced with the three experimental media (NG DMEM, HG DMEM and HM DMEM).

On days 1,3,5 and 7, the cells were washed with PBS and incubated with $500 \mu \mathrm{l}$ of $0.5 \mathrm{mg} / \mathrm{ml}$ MTT (Sigma-Aldrich; Merck Millipore, Darmstadt, Germany) for $2 \mathrm{~h}$ at $37^{\circ} \mathrm{C}$. The cells were rinsed again with PBS. The formazan products were dissolved in $500 \mu \mathrm{l}$ of dimethyl sulfoxide (Sigma-Aldrich; Merck Millipore) for $30 \mathrm{~min}$ at room temperature with agitation. The absorbance at $540 \mathrm{~nm}$ was determined using an Epoch $^{\mathrm{TM}}$ microplate spectrophotometer (Biotek Instruments, Winooski, VT, USA). All assays were performed in triplicate.

Osteogenic differentiation. To induce osteogenic differentiation, the HPDLFs were seeded in 24-well plates $\left(\right.$ Costar $^{\circledR}$; Corning Incorporated) at a density of $5 \times 10^{4}$ cells/well in a humidified atmosphere at $5 \% \mathrm{CO}_{2}$ at $37^{\circ} \mathrm{C}$. When the cells reached $90 \%$ confluence (day 0), they were induced with $50 \mu \mathrm{g} / \mathrm{ml}$ ascorbic acid (Sigma-Aldrich; Merck Millipore), $10 \mathrm{mM} \beta$-glycerophosphate (Sigma-Aldrich; Merck Millipore) and $100 \mathrm{nM}$ dexamethasone (Sigma-Aldrich; Merck Millipore) in each type of DMEM. The medium was replaced every 2-3 days.

Measurement of alkaline phosphatase activity. Following induction of the HPDLFs with osteogenic medium for 7, 14 and 21 days, the cells were analyzed for alkaline phosphatase activity. All groups of HPDLFs were scraped from culture and transferred into microtubes, washed twice with $1 \mathrm{X}$ PBS, and lysed with $200 \mu 1$ lysis buffer containing $1 \mathrm{mM}$ phenylmethanesulfonyl fluoride (Sigma-Aldrich; Merck Millipore) in CelLytic M (Sigma-Aldrich; Merck Millipore) for $15 \mathrm{~min}$ at room temperature. The lysed cells were centrifuged at $20,598 \times \mathrm{g}$ for $15 \mathrm{~min}$ at $4^{\circ} \mathrm{C}$. The supernatant was stored at $-80^{\circ} \mathrm{C}$ until use. To measure alkaline phosphatase activity, $50 \mu 1$ of the sample supernatant was diluted with $50 \mu 10.1 \mathrm{M}$ Tris-HCl, followed by the addition of $50 \mu \mathrm{l}$ $2 \mathrm{mM}$ p-nitrophenol phosphate substrate (Sigma-Aldrich; Merck Millipore) and incubation at $37^{\circ} \mathrm{C}$ for $30 \mathrm{~min}$. The reaction was terminated by adding $50 \mu \mathrm{l}$ ice-cold $2 \mathrm{~N} \mathrm{NaOH}$. The absorbance was measured at $450 \mathrm{~nm}$. The alkaline phosphatase concentration was calculated from the standard curve of p-nitrophenol (Sigma-Aldrich; Merck Millipore). The alkaline phosphatase activity was calculated in U/nmol p-nitrophenol/mg protein $/ \mathrm{min}$. The alkaline phosphatase activity of the induced HPDLFs was then divided by the basal alkaline phosphatase activity to normalize the difference between the passages of cells. All assays were performed in triplicate.
Nodule formation. The induced HPDLFs were evaluated for calcified nodule formation following induction with osteogenic medium for 28 days. All groups of HPDLFs were washed twice with 1X PBS. The cells were fixed with cold absolute methanol at room temperature for $10 \mathrm{~min}$ and rinsed twice with distilled deionized water. The calcified nodules were stained with $1 \%$ Alizarin Red (pH 4.1-4.3; Sigma-Aldrich; Merck Millipore) at room temperature for $30 \mathrm{~min}$. The excess dye was removed and nodules were rinsed with distilled deionized water until the background became clear. The presence of nodules was observed under an inverted microscope (Nikon Corporation, Tokyo, Japan). All experiments were performed at least three times.

Reverse transcription-quantitative polymerase chain reaction $(R T-q P C R)$ analysis. To analyze gene expression following the induction of HPDLFs with osteogenic medium for 3 days, RNA was extracted using TRIzol ${ }^{\circledR}$ reagent (Invitrogen; Thermo Fisher Scientific, Inc.) according to the manufacturer's protocol. The concentration and purity of RNA was determined from the ratio of optical density $(\mathrm{OD})_{260} / \mathrm{OD}_{280}$ using an Epoch $^{\mathrm{TM}}$ microplate spectrophotometer (Biotek Instruments).

Contaminating DNA was removed by DNase I (Fermentas; Thermo Fisher Scientific, Inc.). The prepared RNA was then used as a template for RT to cDNA using iScript selected cDNA synthesis kits (Bio-Rad Laboratories, Inc., Hercules, CA, USA) according to the manufacturer's protocol. Briefly, cDNA was reverse transcribed in iScript reaction mix containing iScript reverse transcriptase together with oligo dT primer, followed by incubation at $42^{\circ} \mathrm{C}$ for $90 \mathrm{~min}$ and $85^{\circ} \mathrm{C}$ for $5 \mathrm{~min}$.

The subsequent qPCR was performed in a StepOnePlus ${ }^{\mathrm{TM}}$ RealTime PCR system (Applied Biosystems; Thermo Fisher Scientific, Inc.) to compare the expression of stem cell marker CD166, periodontal ligament cell marker PERIOSTIN and signaling molecule $\beta$-CATENIN between cells treated with different glucose concentrations using the primers shown in Table I (9-15). The 20- $\mu$ l cocktail contained $10 \mu \mathrm{l} 2 \mathrm{X}$ Maxima ${ }^{\circledR}$ SYBR green master mix with ROX (Thermo Fisher Scientific, Inc.) $0.25 \mu \mathrm{M}$ forward and reverse primers, and $50 \mathrm{ng}$ cDNA. The reactions were initially preheated at $95^{\circ} \mathrm{C}$ for $10 \mathrm{~min}$ followed by 60 cycles of denaturation at $95^{\circ} \mathrm{C}$ for $30 \mathrm{sec}$, annealing at the annealing temperature of each primer (Table I) for $30 \mathrm{sec}$ and extension at $72^{\circ} \mathrm{C}$ for $30 \mathrm{sec}$. The comparative quantification cycle (16) was further analyzed for gene expression by using $\beta$-ACTIN as an internal control.

Statistical analysis. Cell proliferation, gene expression and alkaline phosphatase activity were first analyzed for data distribution using the Shapiro-Wilk Test and the homogeneity of variance. Differences between groups were analyzed using an independent-samples median test and pairwise comparisons of groups using SPSS software version 18 (SPSS Inc., Chicago, IL, USA). $\mathrm{P}<0.05$ was considered to indicate a statistically significant difference.

\section{Results}

Growth of HPDLFs in different glucose conditions. The HPDLFs were cultured in DMEM containing three concentrations of glucose (NG, HM and HG), as described above. 
Table I. Primers used for reverse transcription-quantitative polymerase chain reaction analysis.

\begin{tabular}{|c|c|c|c|c|c|}
\hline Author, year & Target gene & Primer sequence & $\begin{array}{l}\text { Length } \\
\text { (bp) }\end{array}$ & $\begin{array}{l}\text { Annealing } \\
\text { temp. }\left({ }^{\circ} \mathrm{C}\right)\end{array}$ & Refs. \\
\hline \multirow[t]{2}{*}{ Cao et al } & $\begin{array}{l}\text { Stem cell marker } \\
\text { OCT4 (pou5f1) }\end{array}$ & $\begin{array}{l}\text { F 5'-TATACACAGGCCGATGTGG-3' } \\
\text { R 5'-GTGCATAGTCGCTGCTTGA-3' }\end{array}$ & 397 & 60 & (9) \\
\hline & NANOG & $\begin{array}{l}\text { F 5'-ATGCCTCACACGGAGACTG-3' } \\
\text { R 5'-CTGCGTCACACCATTGCTA-3' }\end{array}$ & 369 & 60 & \\
\hline Saigusa et al & SOX2 & $\begin{array}{l}\text { F 5'-CAAGATGCACAACTCGGAGA-3' } \\
\text { R 5'-GCTTAGCCTCGTCGATGAAC-3' }\end{array}$ & 95 & 60 & (10) \\
\hline Rada et al & STROI & $\begin{array}{l}\text { F 5'-GAAGCTAAAGTGGATTCAGGAGTA-3' } \\
\text { R 5'-TAAGCAGGGGACCATTACA-3' }\end{array}$ & 216 & 58 & (11) \\
\hline Wang et al & $C D 166$ & $\begin{array}{l}\text { F 5'-GAATGTCTCTGCTATAAGTATTCCAG-3' } \\
\text { R 5'-GTACAGCCAGTAGACGACACCAGCAAC-3' }\end{array}$ & 157 & 62 & (12) \\
\hline & $\begin{array}{l}\text { Periodontal } \\
\text { ligament } \\
\text { cell marker }\end{array}$ & & & & \\
\hline Dobreva et al & PERIOSTIN & $\begin{array}{l}\text { F 5'-GAAAGGGAGTAAGCAAGGGAG-3' } \\
\text { R 5'-ATAATGTCCAGTCTCCAGGTTG-3' }\end{array}$ & 179 & 58 & (13) \\
\hline Chen et al & $\begin{array}{l}\text { Signaling molecule } \\
\beta \text {-CATENIN }\end{array}$ & $\begin{array}{l}\text { F 5'-AATCTTGCCCTTTGTCCCG-3' } \\
\text { R 5'-GGTTGTGAACATCCCGAGC-3' }\end{array}$ & 214 & 60 & (14) \\
\hline Herath et al & $\begin{array}{l}\text { Internal control } \\
\beta \text {-ACTIN }\end{array}$ & $\begin{array}{l}\text { F 5'-TTGGCAATGAGCGGTT-3' } \\
\text { R 5'-AGTTGAAGGTAGTTTCGTGGAT-3' }\end{array}$ & 93 & 60 & (15) \\
\hline
\end{tabular}

OCT4, octamer-binding transcription factor 4; SOX2, (sex determining region Y)-box 2; CD166, cluster of differentiation 166.

The HPDLFs showed higher proliferation rates when grown in the HG medium, compared with cells grown in the NG or HM medium, however the differences were not statistically significant (Fig. 1).

Stemness gene expression in different glucose conditions. The embryonic stem cell markers (OCT4, NANOG and SOX2) and CD166 mesenchymal stem cell marker were significantly upregulated following 3 days of induction under HG conditions, compared with NG and HM conditions (Fig. 2A-D).

Osteogenic differentiation under different glucose conditions. The alkaline phosphatase activity showed that HPDLFs started to differentiate following induction with osteogenic medium for 7 days (Fig. 3). The alkaline phosphatase activities in all groups showed similar patterns, with the highest activities of alkaline phosphatase found on day 7. Subsequently, activity progressively decreased on days 14 and 21, as shown in Fig. 3. However, the alkaline phosphatase activity in the HG medium appeared to decrease more slowly, compared with that in the other groups.

Following the induction of HPDLFs with osteogenic medium for 28 days, higher numbers of calcified nodules were formed in the HG medium, compared with the numbers formed in the NG and HM media, as shown in Fig. 4.

Expression of PERIOSTIN and $\beta$-CATENIN. As periostin is a marker of periodontal ligament integrity and $\beta$-catenin is a signaling molecule associated with osteogenesis, the

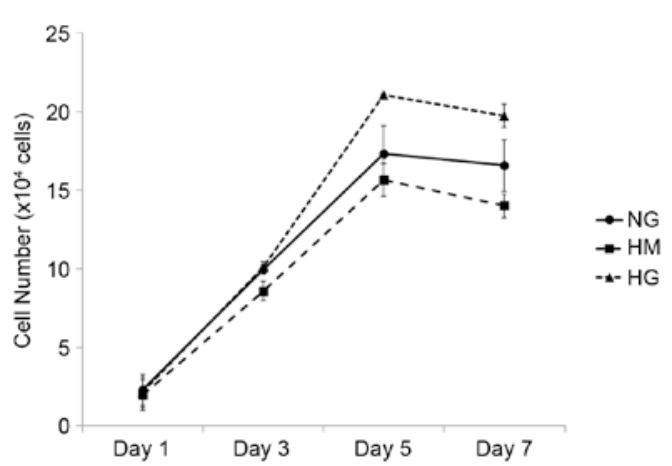

Figure 1. Proliferation of human periodontal ligament fibroblasts cultured in DMEM containing NG, HM and HG concentrations. No statistically significant differences were found when compared with NG. Data are presented as the mean \pm standard error. NG, normal glucose; HM, high mannitol; HG, high glucose.

expression of PERIOSTIN and $\beta$-CATENIN were also examined in the present study. HG induced the HPDLFs to express significantly higher levels of PERIOSTIN, compared with NG and HM (Fig. 5A). Furthermore, the HPDLFs showed significantly higher expression of $\beta$-CATENIN in HG (Fig. 5B).

\section{Discussion}

In the oral cavity, the periodontal ligament anchors the tooth in the alveolar bone. It is an important source of stem cells, 
A
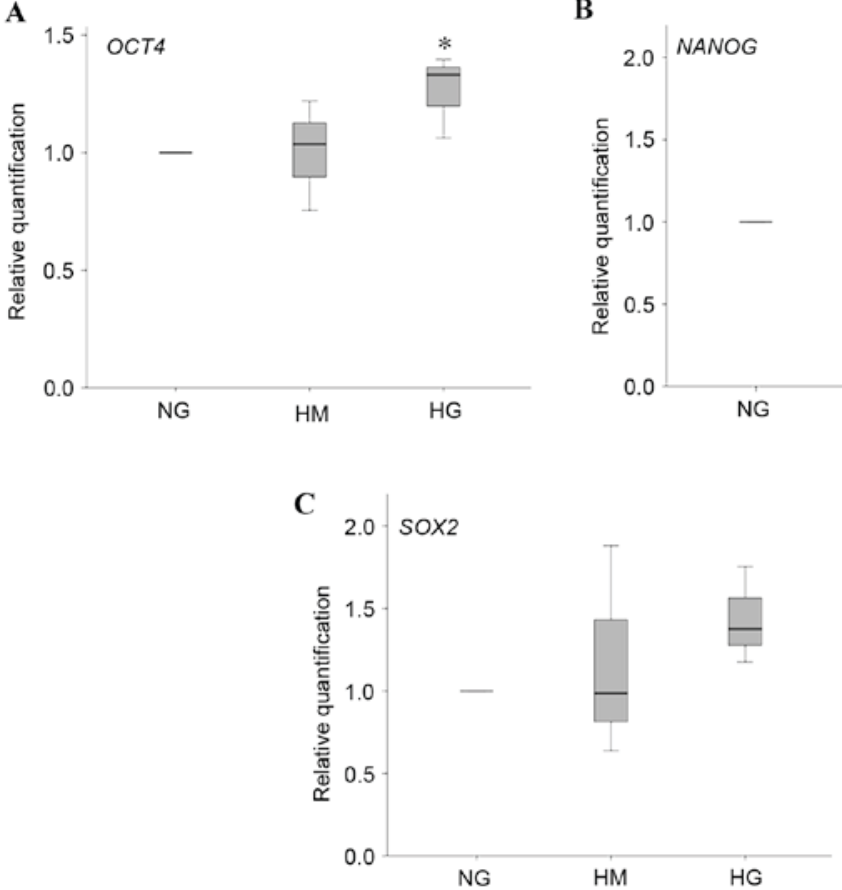

D

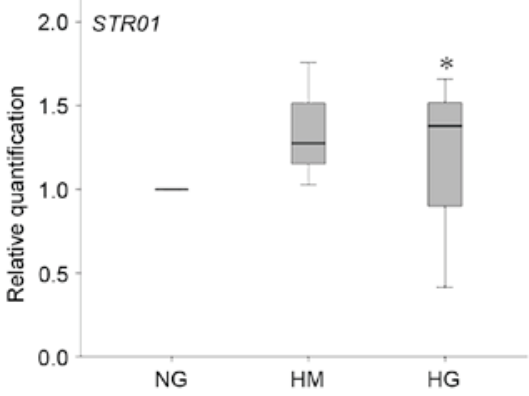

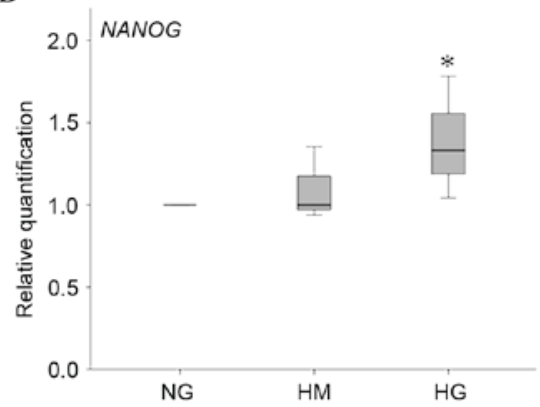

E

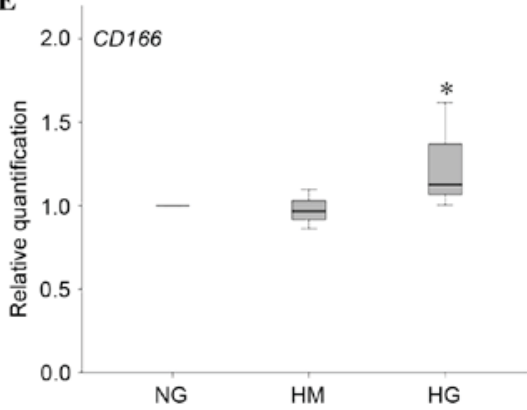

Figure 2. Expression levels of embryonic and mesenchymal stem cell markers. Expression of embryonic markers (A) OCT4, (B) NANOG and (C) SOX2, and mesenchymal markers (D) STRO1 and (E) CD166 of HPDLFs cultured in osteogenic medium containing NG, HM and HG concentrations for 3 days. Data are presented as the median and range. "P<0.05, compared with NG. OCT4, octamer-binding transcription factor 4; SOX2, (sex-determining region Y)-box 2; CD166, cluster of differentiation 166; NG, normal glucose; HM, high mannitol; HG, high glucose.

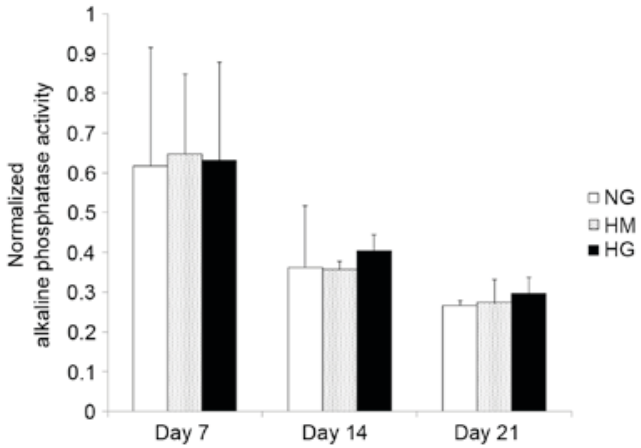

Figure 3. Alkaline phosphatase activity of human periodontal ligament fibroblasts cultured in osteogenic medium containing normal glucose NG, HM and HG concentration for 7, 14 and 21 days. No statistically significant differences were found when compared with NG. Data are presented as the mean \pm standard error. NG, normal glucose; HM, high mannitol; HG, high glucose.

lying between the alveolar bone and the cementum, which is involved in regeneration by differentiating to replace the destroyed attachment tissue. As HPDLFs are readily obtained from extracted teeth by scraping the periodontal tissue out from the root of extracted teeth, they offer potential as a source of adult stem cells. HPDLFs have been reported to possess mesenchymal stem cell properties, as they can differentiate into osteoblasts, adipocytes, chondrocytes and neurons (3-5). However, their differentiation activities under different glucose conditions remain to be fully elucidated. As the progression of periodontitis destroys periodontal tissue, increased alveolar bone loss has been found in diabetic patients with poor glycemic control (2). The effect of high glucose conditions has been investigated in several cell types, including fibroblasts (6-8). Therefore, the regeneration processes of periodontal ligament tissue may be affected in periodontitis, particularly in patients with poor glycemic control.

In the present study, HPDLFs in the HG medium tended to proliferate more, compared with those in the NG and HM medium, although differences were not statistically significant. The glucose concentrations used in the present study simulated the normal blood glucose levels found in healthy individuals $(100 \mathrm{mg} / \mathrm{dl})$ and the high blood glucose level found in diabetic patients $(400 \mathrm{mg} / \mathrm{dl})$. The higher proliferation rate in the HG 


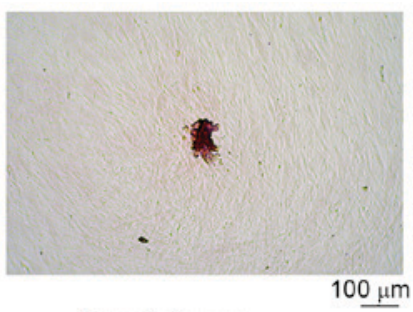

Normal glucose

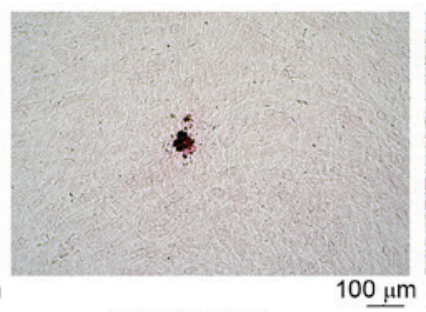

High mannitol

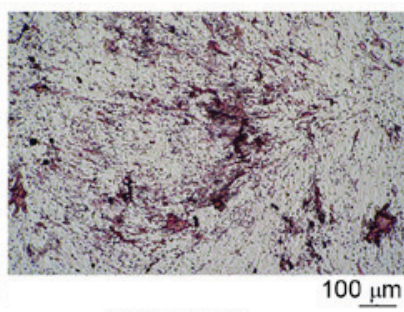

High glucose

Figure 4. Calcified nodules stained with $1 \%$ Alizarin Red from human periodontal ligament fibroblasts on day 28 of osteogenic induction in normal glucose, high mannitol and high glucose conditions.
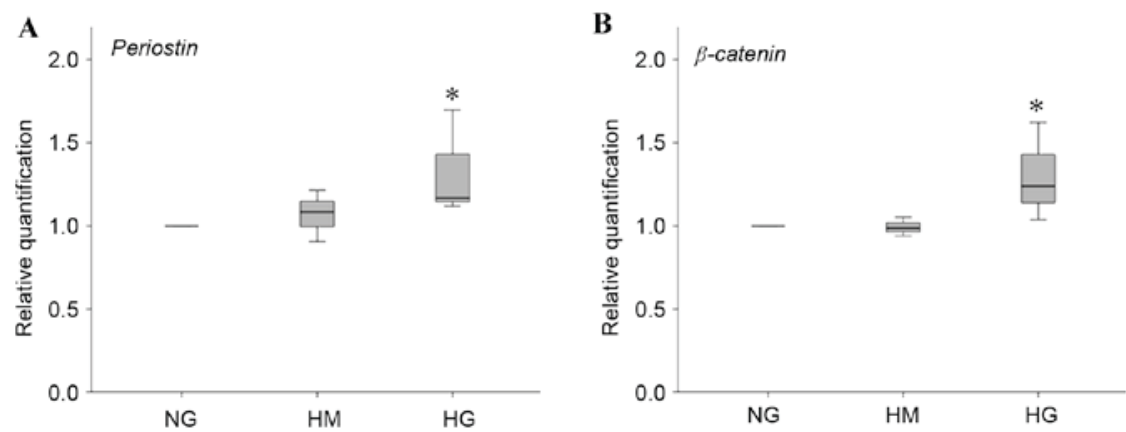

Figure 5. Relative quantification of Periostin and $\beta$-catenin. Relative quantification of (A) Periostin and (B) $\beta$-catenin was determined using reverse transcription-quantitative polymerase chain reaction analysis following osteogenesis of human periodontal ligament fibroblasts for 3 days in NG, HM and HG. Data are presented as the median and range. "P<0.05, compared with NG. NG, normal glucose; HM, high mannitol; HG, high glucose.

group was not unexpected, as glucose is an energy source for all cells. In addition, the HM group, an osmotic pressure control group, showed the same effect as the NG group. This suggested that the higher growth rate was due to the effect of glucose and not the effect of osmotic pressure. Previous studies on mouse bone mesenchymal stem cells support these findings, which showed that $25 \mathrm{mM}$ glucose-containing medium promoted growth of cells on day 17 (17). These findings suggest that high glucose conditions alone, as found in diabetic patients, may not harm the growth of PDLFs.

When HPDLFs were induced with osteogenic medium for 3 days, the embryonic stem cell markers, OCT4, NANOG and $S O X 2$, were upregulated in the HG condition, similar to the results reported by Madonna et al in 2014 (18). These results showed that HG levels can enhance the expression of embryonic stem cell markers in HPDLFs at early stages of osteogenesis. The mesenchymal stem cell marker, CD166, was also upregulated on day 3 . The upregulation of stem cell marker genes may be associated with the potential of cells to differentiate, which correlates with the increased number of calcified nodules formed in this condition at later stages. In addition, Saito et al in 2014 (19) suggested that the expression of CD166 is associated with the capacity of cells to differentiate into osteoblasts/cementoblasts.

Following osteogenic induction for 14 days, the HPDLFs in the HG concentration medium expressed higher levels of alkaline phosphatase activity, compared with those in the NG and HM media. Again, this suggested that the increased alkaline phosphatase activity was due to the metabolic activity of cells, whereas increased osmotic pressure did not affect activity. On day 28 , higher numbers of calcified nodules were also formed in the HG condition, compared with those in the NG condition. In 2014, $\mathrm{Li}$ and $\mathrm{Li}$ (17) also showed that periodontal ligament cells cultured under HG conditions also had higher alkaline phosphatase activities on days 14 and 21, but found that fewer nodules were formed in the HG medium. These differences may be due to the different sources of cells and their ability to express stem cell markers. In the present study, following induction, the cells started to differentiate and form calcified nodules. The HG condition was found to stimulate the formation of calcified nodules, and this may be due to higher metabolic activity producing more ATP and increasing calcium transport into cells, which leads to increased calcium concentration inside cells, followed by calcium deposition.

In terms of the association between diabetes and periodontal disease in bone metabolism (20), diabetic animals show delayed bone healing. Patients with diabetes have been shown to have lower radial bone density, compared with non-diabetic patients (21). By contrast, the results of the present study showed the enhancement of osteogenesis in HPFLFs cultured in HG medium. However, other factors may also require consideration in examining the effect of the diabetic condition on cells. Diabetic animals may not only exhibit hyperglycemia, but may exhibit other conditions, including the production of advanced glycation end products, lipotoxicity from long-chain free fatty acids and immune responses due to the diabetic condition. Consequently, the HG levels alone may not have been sufficient to negatively affect the osteogenic differentiation of HPDLFs in the present study, compared with diabetic animals. Cells under chronic diabetic conditions may have alterations in protein modification, which lead to a different response to hyperglycemia, compared with the response of cells in 
in vitro $\mathrm{HG}$ conditions. Intracellular hyperglycemia initiates intracellular and extracellular advanced glycation end product formation. In addition, several immune cells in the body of animals and humans respond to hyperglycemia. Neutrophils in diabetic patients with moderate and poor diabetic control have been found to release higher levels of superoxide, compared with healthy subjects (22). Thus, it is possible that fibroblasts in vitro may respond differently to $\mathrm{HG}$, compared with in vivo. The cocktail of inflammatory cytokines secreted may also affect in vivo results. An example of this is the increased level of TNF- $\alpha$ in a diabetic mouse model, which induces the apoptosis of mesenchymal stem cells (23).

The findings of the present study have various implications. In terms of clinical implications, the results showed that $\mathrm{HG}$ increased all cellular processes, including the proliferation and differentiation of HPDLFs. Therefore, in diabetic patients with periodontitis, once the periodontal pathogen has been removed and inflammation subsides, HPDLFs can differentiate into the osteoblast lineage, which assists in bone regeneration. Intensive periodontal therapy can significantly reduce periodontal indices and $\mathrm{HbA} 1 \mathrm{c}$ in diabetic patients with moderate periodontitis (24).

The in vitro results of the present study are also of interest in terms of cell-based experiments as HG caused HPDLFs to differentiate into osteoblasts and form calcified nodules. Accordingly, the glucose level in the medium may be important when examining the process of osteogenesis in cells.

Periostin is a tissue specific protein in periodontal ligaments (25). It is reported to be secreted in adipose tissue and is significantly positively correlated with blood glucose levels in obese rats (Psammomys obesus) with type 2 diabetes mellitus (26). In addition, a study by Horiuchi et al in 1999 (27) suggested that periostin is involved in the recruitment and attachment of osteoblast precursors. The results of the present study showed increased expression of PERIOSTIN in the HG osteogenic medium. This suggested that the cells retained tissue specific origin, and that this protein may be involved in osteogenic differentiation in HG medium.

The results of the present study also showed that $\beta$-CATENIN was upregulated in HG medium. As several reports (28-30) have suggested that Wnt/ $\beta$-catenin is involved in osteogenesis, HG conditions may induce osteoblast differentiation in HPDLFs through the Wnt/ $\beta$-catenin pathway. However, further studies are required to understand the mechanisms involved.

In terms of tissue regeneration in diabetes and periodontitis, the results of the present study showed that HG increased all cellular processes, including the proliferation and differentiation of HPDLFs. Therefore, in diabetic patients with periodontitis, once the periodontal pathogen has been removed and inflammation subsides, HPDLFs can differentiate into the osteoblast lineage, which will assist bone regeneration. Thus, intensive periodontal therapy can significantly reduce periodontal indices and HbA1c in diabetic patients with moderate periodontitis (24). The results of the present study also suggested that calcification in cell-based transplantation may be performed successfully in diabetic patients. Furthermore, reagents associated with the $\mathrm{Wnt} / \beta$-catenin pathway may be useful in stem cell therapy to assist in inducing osteogenic differentiation, as suggested by Liu et al in 2015 (31). This may improve the treatment of bone regeneration in the future.
In conclusion, the present study indicated that HG medium (25 mM) was non-toxic to HPDLFs. The HPDLFs responded to $\mathrm{HG}$ conditions by increasing the expression of embryonic and mesenchymal stem cell markers, as well as the tissue specific protein, periostin. Calcified nodules were also formed in higher numbers when the cells were induced in osteogenic medium containing HG concentration. This effect may be regulated by $\beta$-catenin, which was induced by HG levels. Further investigation of HPDLFs transplantation in animal models is required to confirm these in vitro results. However, these cells are likely to be useful for tissue regeneration in diabetic patients.

\section{Acknowledgements}

The present study was supported by the project for Higher Education Research Promotion and National Research University Development, the Office of the Higher Education Commission and the Thailand and Mahidol University Medical Scholar Program.

\section{References}

1. Taylor GW, Burt BA, Becker MP, Genco RJ and Shlossman M: Glycemic control and alveolar bone loss progression in type 2 diabetes. Ann Periodontol 3: 30-39, 1998.

2. Taylor GW, Burt BA, Becker MP, Genco RJ, Shlossman M, Knowler WC and Pettitt DJ: Non-insulin dependent diabetes mellitus and alveolar bone loss progression over 2 years. J Periodontol 69: 76-83, 1998.

3. Kim SS, Kwon DW, Im I, Kim YD, Hwang DS, Holliday LS, Donatelli RE, Son WS and Jun ES: Differentiation and characteristics of undifferentiated mesenchymal stem cells originating from adult premolar periodontal ligaments. Korean J Orthod 42: 307-317, 2012.

4. Park JC, Kim JM, Jung IH, Kim JC, Choi SH, Cho KS and Kim CS: Isolation and characterization of human periodontal ligament (PDL) stem cells (PDLSCs) from the inflamed PDL tissue: In vitro and in vivo evaluations. J Clin Periodontol 38: 721-731, 2011.

5. Nagatomo K, Komaki M, Sekiya I, Sakaguchi Y, Noguchi K, Oda S, Muneta T and Ishikawa I: Stem cell properties of human periodontal ligament cells. J Periodont Res 41: 303-310, 2006.

6. Liu J, Wu Y, Wang B, Yuan X and Fang B: High levels of glucose induced the caspase-3/PARP signaling pathway, leading to apoptosis in human periodontal ligament fibroblasts. Cell Biochem Biophys 66: 229-237, 2013.

7. Liu J, Jiang Y, Mao J, Gu B, Liu H and Fang B: High levels of glucose induces a dose-dependent apoptosis in human periodontal ligament fibroblasts by activating caspase-3 signaling pathway. Appl Biochem Biotechnol 170: 1458-1471, 2013.

8. Nishimura F, Terranova V, Foo H, Kuriharal M, Kuriharal H and Murayama Y: Glucose-mediated alteration of cellular function in human periodontal ligament cells. J Dent Res 75: 1664-1671, 1996.

9. Cao H, Xu W, Qian H, Zhu W, Yan Y, Zhou H, Zhang X, Xu X, Li J, Chen Z and Xu X: Mesenchymal stem cell-like cells derived from human gastric cancer tissues. Cancer Lett 274: 61-71, 2009.

10. Saigusa S, Tanaka K, Toiyama Y, Yokoe T, Okugawa Y, Ioue Y, Miki C and Kusunoki M: Correlation of CD133, OCT4 and SOX2 in rectal cancer and their association with distant recurrence after chemoradiotherapy. Ann Surg Oncol 16: 3488-3498, 2009.

11. Rada T, Reis RL and Gomes ME: Distinct stem cells subpopulations isolated from human adipose tissue exhibit different chondrogenic and osteogenic differentiation potential. Stem Cell Rev 7: 64-76, 2011.

12. Wang J, Gu Z, Ni P, Qiao Y, Chen C, Liu X, Lin J, Chen N and Fan Q: NF-kappaB P50/P65 hetero-dimer mediates differential regulation of CD166/ALCAM expression via interaction with micoRNA-9 after serum deprivation, providing evidence for a novel negative auto-regulatory loop. Nucleic Acids Res 39: 6440-6455, 2011. 
13. Dobreva MP, Lhoest L, Pereira PN, Umans L, Camus A, Chuva de Sousa Lopes SM and Zwijsen A: Periostin as a biomarker of the amniotic membrane. Stem Cells Int 2012: 987185, 2012.

14. Chen X, Hu C, Wang G, Li L, Kong X, Ding Y and Jin Y: Nuclear factor- $\kappa \mathrm{B}$ modulates osteogenesis of periodontal ligament stem cells through competition with $\beta$-catenin signaling in inflammatory microenvironments. Cell Death Dis 4: e510, 2013.

15. Herath TD, Wang Y, Seneviratne CJ,Lu Q, Darveau RP, Wang CY and Jin L: Porphyromonas gingivalis lipopolysaccharide lipid a heterogeneity differentially modulates the expression of IL-6 and IL-8 in human gingival fibroblasts. J Clin Periodontol 38: 694-701, 2011.

16. Livak KJ and Schmittgen TD: Analysis of relative gene expression data using real-time quantitative PCR and the 2(-Delta Delta C(T)) Method. Methods 25: 402-408, 2001

17. Li M and Li CZ: High glucose improves healing of periodontal wound by inhibiting proliferation and osteogenetic differentiation of human PDL cells. Int Wound J 13: 39-43, 2016.

18. Madonna R, Geng YJ, Shelat H, Ferdinandy P and De Caterina R: High glucose-induced hyperosmolarity impacts proliferation, cytoskeleton remodeling and migration of human induced pluripotent stem cells via aquaporin-1. Biochim Biophys Acta 1842: 2266-2275, 2014

19. Saito MT, Salmon CR, Amorim BR, Ambrosano GM, Casati MZ, Sallum EA, Nociti FH and Silvério KG: Characterization of highly osteoblast/cementoblast cell clones from a CD105-enriched periodontal ligament progenitor cell population. J Periodontol 85: e205-e211, 2014

20. Wu YY, Xiao E and Graves DT: Diabetes mellitus related bone metabolism and periodontal disease. Int J Oral Sci 7: 63-72, 2015.

21. Krakauer JC,McKenna MJ,Buderer NF, Rao DS, Whitehouse FW and Parfitt AM: Bone loss and bone turnover in diabetes. Diabetes 44: 775-782, 1995.

22. Karima M, Kantarci A, Ohira T, Hasturk H, Jones VL, Nam BH, Malabanan A, Trackman PC, Badwey JA and Van Dyke TE: Enhanced superoxide release and elevated protein kinase $C$ activity in neutrophils from diabetic patients: Association with periodontitis. J Leukoc Biol 78: 862-870, 2005.
23. Ko KI, Coimbra LS, Tian C, Alblowi J, Kayal RA, Einhorn TA, Gerstenfeld LC, Pignolo RJ and Graves DT: Diabetes reduces mesenchymal stem cells in fracture healing through a TNFo-mediated mechanism. Diabetologia 58: 633-642, 2015

24. Calabrese N, D'Aiuto F, Calabrese A, Patel K, Calabrese G and Massi-Benedetti M: Effects of periodontal therapy on glucose management in people with diabetes mellitus. Diabetes Metab 37: 456-459, 2011

25. Han X and Amar S: Identification of genes differentially expressed in cultured human periodontal ligament fibroblasts vs. human gingival fibroblasts by DNA microarray analysis. J Dent Res 81: 399-405, 2002.

26. Bolton K, Segal D, McMillan J, Sanigorski A, Collier G and Walder K: Identification of secreted proteins associated with obesity and type 2 diabetes in Psammomys obesus. Int J Obes (Lond) 33: 1153-1165, 2009.

27. Horiuchi K, Amizuka N, Takeshita S, Takamatsu H, Katsuura M, Ozawa H, Toyama Y, Bonewald LF and Kudo A: Identification and characterization of a novel protein, periostin, with restricted expression to periosteum and periodontal ligament and increased expression by transforming growth factor beta. J Bone Miner Res 14: 1239-1249, 1999.

28. Heo JS, Lee SY and Lee JC: Wnt//-catenin signaling enhances osteoblastogenic differentiation from human periodontal ligament fibroblasts. Mol Cells 30: 449-454, 2010.

29. Liu N, Shi S, Deng M, Tang L, Zhang G, Liu N, Ding B, Liu W, Liu Y, Shi H, et al: High levels of $\beta$-catenin signaling reduce osteogenic differentiation of stem cells in inflammatory microenvironments through inhibition of the noncanonical Wnt pathway. J Bone Miner Res 26: 2082-2095, 2011.

30. Liu W, Konermann A, Guo T, Jäger A,Zhang Land Jin Y: Canonical Wnt signaling differently modulates osteogenic differentiation of mesenchymal stem cells derived from bone marrow and from periodontal ligament under inflammatory conditions. Biochim Biophys Acta 1840: 1125-1134, 2014.

31. Liu Q, Hu CH, Zhou CH, Cui XX, Yang K, Deng C, Xia JJ, Wu Y, Liu LC and Jin Y: DKK1 rescues osteogenic differentiation of mesenchymal stem cells isolated from periodontal ligaments of patients with diabetes mellitus induced periodontitis. Sci Rep 5: 13142, 2015. 